\title{
The Long-Term Effects of Early Track Choice
}

\author{
Christian Dustmann, Patrick A. Puhani and Uta Schönberg*
}

November 5, 2015

\begin{abstract}
We investigate the effects of attending a more advanced track in middle school on long-term education and labor market outcomes for Germany, a country with a rigorous early-age tracking system, where the risk of misallocating students to tracks is particularly high. Our research design exploits quasi-random shifts between tracks induced by date of birth, and speaks to the long-term effects of early track attendance for a group of marginal students most at risk of misallocation. Remarkably, we find no evidence that attending a more advanced track leads to more favourable long-term outcomes. We attribute this result to the possibility of later track-reversal.
\end{abstract}

JEL No.: I21, J10

Keywords: tracking, school quality, peer effects, regression discontinuity design

*Dustmann: Department of Economics, University College London, c.dustmann@ucl.ac.uk. Puhani: Leibniz Universität Hannover, Institut fur Arbeitsökonomik, Königsworther Platz 1, 30167 Hannover, Germany, puhani@aoek.uni-hannover.de. Schönberg: Department of Economics, University College London and Institute for Employment Research, u.schoenberg@ucl.ac.uk. Part of this research was supported by the Fritz Thyssen Foundation and the German Research Foundation (DFG). 


\section{INTRODUCTION}

Countries differ widely with respect to the way they organise their school systems. While Germany and Singapore deliberately track students into different schools based on ability as early as the end of elementary school (ages 10/12), other countries, such as the U.S., the U.K., and Japan, essentially keep their entire secondary education system comprehensive. Proponents of tracking systems stress that allocating students to learning environments more adequate for their abilities can lead to more efficient educational production, whereas opponents argue that tracking may exacerbate initial disadvantages. Most particularly, they point to the danger that small differences between students in innate ability or social background before tracking may translate into large differences in adult outcomes through exposure to very different learning environments. This problem is particularly acute in a system that tracks students very early on, when information about the student's learning potential is likely to be incomplete and track allocation is, at least to some extent, determined by sheer luck. But initial mis-tracking need not lead to life-long disadvantage, as long as the tracking system has built-in flexibilities that allow correction of initial choices at a later point, and when more information about individuals' abilities is available. This important aspect in assessing tracking systems has hardly been discussed in the literature so far.

Thus, to assess whether early track allocation has indeed life-long consequences, and whether a tracking system successfully allows for correcting initial misallocations, requires a comparison of long-term educational and labour market outcomes of individuals who were at the margin between two tracks, and who were randomly allocated into a higher or a lower track. It is such a natural experiment on which we draw in this paper. We explore this for Germany, a country with a particularly rigorous tracking system that very early on (at age 10) allocates students into three different school tracks based on ability and locks them into the assigned track throughout middle school (i.e., from grades 5 to 9). These tracks are designed to support particular career paths: the high track prepares students for college or 
university education, while the medium and low tracks aim at providing skills for white and blue collar apprenticeships. As a result, the three tracks differ widely, especially in terms of teaching curricula as well as peer and teacher quality.

Our research design exploits quasi-random shifts between tracks induced by date of birth. Based on this design, discussed in detail in Section 3.1, we can identify (a lower bound of) the causal effect of track exposure for students who are at the margin between two tracks (hereafter, marginal students). These are students whose parents or teachers may be unsure of which track the student should attend after elementary school and who are therefore most at risk of misallocation. We first show that children who are born after the age of school entry cut-off date are more likely to attend a more advanced track in middle school than children who are born before the age of school entry cut-off date, and who are thus younger in class. This is the first stage of our analysis. We then investigate the impact of date of birth on long-term labour market outcomes and educational attainment, obtaining reduced form estimates. Despite the differences in learning environments between tracks and a strong first stage, we find that date of birth has no effect on wages, employment or occupation choice at later ages. This suggests that, for students at the margin between two tracks, attending a more advanced track in middle school bears little benefits later in life.

What explains this surprising finding? We attribute it to the up- and downgrading of students between tracks that takes place at a later stage of their educational career: We first show a substantial amount of movement from the low or medium to the high track at the end of middle school (age 15/16), an upgrading facilitated by the school system. We further demonstrate a substantial amount of downgrading at the age of 18/19 through nonenrollment in college or university after graduating from the high track. Due to this upand downgrading, attending a more advanced track induced by birth date has, for marginal students, hardly any impact on the probability of graduating from a medium or high track, completing an apprenticeship, or graduating from college or university. These findings of zero 
effects on long-term outcomes for marginal students do not imply that there is no difference in observed outcomes of students who sort into different tracks in middle school: Our own calculations based on the German Socio-Economic Panel show that these differences are large, reflecting the ability-based selection that characterises a tracking system. ${ }^{1}$

These findings emphasise a core aspect of the basis on which tracking systems should be assessed: the built-in possibilities to correct earlier allocations at a stage when more information is revealed about a student's true potential. That is, although the young age at which the tracking decision is taken creates particularly large risks for student misallocation, the system we study also allows students whose potential has been erroneously assessed to revise the initial track decision at later stages in their educational careers. Our findings underscore that these built-in flexibilities allow marginal students to fully make up for the exposure to a less challenging school environment during middle school-even if the exposure to a less challenging school environment is prolonged (in our case 5 to 6 years) and the differences in school environments are large.

The paper is structured as follows: Section 2 provides an overview of the relevant literature and the German tracking system. Sections 3 and 4 then outline our empirical research design and data sources, respectively. Section 5 reports the empirical results, and Section 6 presents our discussion and conclusions. Besides reporting additional results in the Appendix, we also provide a theoretical model of track choice which formalises the shifting of students to a different track because of birth month, and clarifies how the key differences between school tracks (i.e., teaching technology and peer quality) may affect long-term outcomes.

\footnotetext{
${ }^{1}$ OLS regressions based on the GSOEP suggest that completing the medium versus the low track is associated with a 16 percent wage differential, whereas completing the high versus the medium track is associated with a 23 percent wage differential.
} 


\section{BACKGROUND}

\subsection{Existing Literature}

The literature on tracking has adopted three approaches to assess the effects of tracking on student outcomes, relying on across-country, within-country and within-school variation. Exploiting variation in school systems across countries, Hanushek and Wössmann (2006) show that the variance of the test score distribution increases between elementary and middle school in countries with a tracked school system relative to countries with a comprehensive school system, without an increase in the mean. They thus conclude that tracking increases achievement of high ability students at the expense of low ability students. Waldinger (2007) argues that these findings are sensitive to the way countries are categorised into a tracked and comprehensive school system.

A number of recent papers evaluate policy reforms which effectively reduced tracking within a country. For instance, while Malamud and Pop-Echeles (2011), Kerr, Pekkarinen, and Uusitalo (2013) and Hall (2012) study the effects of deferring tracking to a later age, Guyon, Maurin and McNally (2012) investigate the effects of an increase in the share of students admitted to the academic (grammar) school track. Both the across-country and within-country studies should be seen as complementary to our paper: While these studies are informative about which students may benefit or lose from a tracked versus a non-tracked school system, or from de-tracking, they do not investigate the long-term consequences initial misallocation to tracks and the role of flexibilities built into a tracking system to remedy such misallocation - which is the focus of this paper.

Studies surveyed comprehensively by Betts (2011) analyze the effects of tracking within schools, as often practiced in the U.S. Most of these earlier studies do not take into account the sorting of students into tracks, or into schools that offer tracking. A study by Duflo, Dupas, and Kremer (2011) addresses this, by randomly allocating schools to tracked and 
non-tracked schools. In tracked schools, students are assigned to the higher track based on a test. Similar to our study, these authors carry out a regression discontinuity design, comparing students whose test results put them at the margin between two tracks. They find no effect of attending the high track on achievement for the marginal student, a result that we complement in our natural experiment for Germany for long-term outcomes. These authors also estimate the impact of within-school tracking on the entire test score distribution, and conclude that all students - including those in the lower track - benefit from tracking. While our research design does not allow us to assess these overall effects of a tracked versus a non-tracked education system, an important advantage of our study is that we are able to estimate the long-term effects (as opposed to the short-term effects, as in Duflo, Dupas, and Kremer, 2011) of attending a more advanced track for a group of marginal students most at risk of misallocation.

Our paper is also related to the literature on school quality; in particular that on elite schools where, similar to Duflo, Dupas, and Kremer (2011), attendance at an elite school is determined by an entry examination. This set-up lends itself to a regression discontinuity design, where the effects of attending an elite school are estimated by comparing outcomes of students who in the entry exam scored just below or just above the attendance cutoff-which are students at the margin between elite and non-elite schools. Previous papers on this issue reach conflicting conclusions. For instance, whereas Jackson (2010) and PopEcheles and Urquiola (2013) find that attending better schools improves children's academic achievement, Clark (2010) and Abdulkadiroglu, Angrist and Pathak (2011) find no evidence that elite schools improve standardised test scores. Since these studies focus on academic achievement before final educational choices are made, they essentially identify a short-term effect of school quality. This effect may differ considerably from the long-term effect of school quality that also depends on subsequent educational choices, which is what we study in this 
paper. $^{2}$

\subsection{General Overview of the German Education System}

Figure 1 provides an overview of the German education system, where students are allocated into three tracks at the end of fourth grade (around the age of 10). We designate these tracks 'high', 'medium', and 'low'. Education in the high track, the Gymnasium (comparable to the traditional British grammar school) lasts for nine years (grades 5 to 13) and prepares students for tertiary studies at such academic institutions as four-year colleges or five-year universities. Education at the low and medium track, on the other hand, lasts five (grades 5 to 9) and six years (grades 5 to 10), respectively, is less academic, and prepares students for an apprenticeship in blue-collar (e.g., crafts) or white-collar occupations (e.g., office clerk, but also medical assistant). For men and women born between 1961 and 1976, the cohorts focused on in the empirical analysis, the shares of who attends each track are roughly of equal size.

Although there is no strict rule (such as an entry exam) to determine which track children can attend after elementary school, elementary school teachers do make recommendations. However, in 10 out of 16 states, parents have the final word on this choice. In the remaining 6 states, if parents want to deviate from the teachers' recommendation, students must either have earned the required marks or pass a special test. ${ }^{3}$

In principle, students may switch between tracks at any grade throughout middle school; however, in practice, very few students (less than $2 \%$ ) do so. ${ }^{4}$ Hence, once students are allocated, they are locked into their chosen track for at least five years. However, once

\footnotetext{
${ }^{2}$ Other studies which exploit quasi-random variation to investigate the short-term effects of school quality on student achievement include Gould, Lavy, and Paserman (2004) and Cullen, Jakob and Levitt (2005, 2006). Recently, a number of studies on the long-term effects of school quality on adult outcomes have emerged (e.g., Chetty, Friedman, Hilger, Saez, Whitmore Schanzenbach and Yagan, 2011; Deming, Hastings, Kaine and Staiger, 2012). Due to a different research design, these studies do not necessarily identify the effects of school quality for the marginal student, and may thus not be directly comparable to our study.

${ }^{3}$ For more information, see http://www.kmk.org/fileadmin/veroeffentlichungen \_beschluesse/2010/2010 \_10 \_18\Uebergang-Grundschule-S \_eI1-Orientierungsstufe.pdf

${ }^{4}$ Own calculations based on the School Census for Bavaria and Hesse.
} 
students complete their course at the low or medium track (i.e., after ninth or tenth grade), the school system facilitates switches between tracks. In particular, at the end of ninth grade, low track students may either switch to a medium track school or, provided that their school offers this possibility, stay on for another year to earn the same school-leaving qualification which they would have received from a medium track school. In addition, after tenth grade, students who graduated from a medium track school may either upgrade to a traditional high track school, or attend a high track school targeted at former medium track students. These latter often provide a special focus (e.g., agricultural, business, health, or social studies) in addition to general education, and we label them 'specialised high track schools' (see Figure 1). Like graduation from a general high track school, graduation from a specialised high track school grants access to college or university, but possibly restricts the field of study.

Two further factors facilitate track switching in the German education system such that students can make up for exposure to a less challenging middle school track. First, legal regulations at the state level limit German universities' ability to pick students from particular schools. Most importantly, school marks are the main criterion for entry into almost all courses of studies and must be taken into account mechanically to assign university placesthat is regardless of whether they are from a traditional or specialised high track school and without concern for the reputation of the high track school. A second facilitating element for track changers is the overwhelmingly state-financed nature of the education system in Germany - as opposed to a largely property-tax funded school system in the U.S. This state financing - which is mostly based on student head counts for both schools and universitiesgenerates a comparatively large equality in the endowment and quality between educational institutions, including universities. In particular, the concept of an elite university eludes Germany for the cohorts we study. ${ }^{5}$

\footnotetext{
${ }^{5}$ Still today, students looking for an elitist education go abroad, mostly to the Anglo-Saxon world.
} 


\subsection{Differences between Tracks}

The first important difference between the three tracks is that they differ with respect to teaching intensity and learning goals. ${ }^{6}$ We summarise the details in Panel A of Table 1. In ninth grade (i.e., when attendance at low track schools ends), the number of hours taught per week is 36 at high, but only 32 at medium and low track schools, respectively. Moreover, although the number of weekly hours in core subjects like Mathematics, German, and English as a foreign language is similar across tracks, high track schools teach more hours in the second and third foreign language and natural sciences, and fewer hours in social sciences, physical education, and vocational subjects (e.g., the 'World of Work') than low or medium track schools. In the core subjects of mathematics and German, tracks differ with respect to the topics taught as well as teaching intensity. For example, whereas low track schools put special emphasis in ninth grade on such applications as writing CVs, filling out forms, and preparing for job interviews, high track schools pay special attention to detailed explanations, analysis, and interpretation of various types of texts, including historical documents, and stress creative writing. Likewise, whereas ninth-grade mathematics in medium track schools covers topics such as real numbers and powers and equations with two unknowns, these topics are taught in eighth grade in high track schools. Similarly, although both medium and high track schools introduce functions, high track schools do so more intensely and cover advanced functions (e.g., exponential and broken power functions) not taught in medium track schools. Low track schools, in contrast, sometimes cover no functions at all, focusing instead on equations with rational numbers.

A second important difference is that students attending the high or medium track are surrounded by academically stronger peers than students attending the low track. According to PISA data for 2003 and 2006, average reading and mathematics test scores at high track

\footnotetext{
${ }^{6}$ The information in this paragraph was gathered from the curricula published on the web pages of the Ministries for Culture and Education of West German states. In some cases, we also contacted the ministries by telephone.
} 
schools are about one standard deviation higher than at medium track schools and about 1.7 standard deviations higher than at low track schools in ninth grade (see Panel B of Table 1). These differences in peer quality across school tracks are far larger than those in the quasi-experiments by Pop-Eleches and Urquiola (2013) and Cullen, Jakob and Levitt (2006) (around 0.20 of a standard deviation in both cases). The figures in the table also show that high track students are exposed to peers whose family backgrounds are more academic than those of potential classmates at medium or low track schools, and that high track students come from higher income households: only 39 percent live in households with a below-median income, a number that increases to 65 percent for medium track students and 76 percent for low track students. ${ }^{7}$ It should also be noted that track choice alone can explain more than 80 percent of the variation in test scores across schools in ninth grade, suggesting that schools of the same type are fairly homogeneous.

A third important difference between the three tracks is that teachers in high track schools are likely to be of higher quality than teachers in medium or low track schools. More specifically, as Panel C of Table 1 shows, the minimum formal education for high track teachers is one year higher than that for low and medium track teachers, and their salaries are approximately 10 percent higher.

\section{Research Design}

\subsection{Randomization into Tracks}

To identify a causal effect, we require an experiment that effectively randomises students of the same ability into different tracks after elementary school. Figure 2 provides an illustration of our natural experiment. Our starting point is that, because of the school entry cut-off rule, children whose birthdays fall before July 1 typically start school a year earlier than

\footnotetext{
${ }^{7}$ Panel B of Table 1 also shows that the share of girls in low track schools is about 14 percentage points lower than in high track schools, which may boost the performance of boys and girls at school (e.g., Schanzenbach, 2009; Lavy and Schlosser, 2011) and in the labor market (Black, Devereux, and Salvanes, 2012).
} 
children whose birthdays are on or after July 1. Hence, although not every child complies with this law, children born shortly after the cut-off date, in July, are on average considerably older at school entry than children born shortly before the cut-off date, in June. A large body of literature has shown that age of school entry is an important determinant of early student achievement; see e.g., Bedard and Dhuey (2006); Puhani and Weber (2007); Elder and Lubotsky (2009); and Schneeweiss and Zweimüller (2014). Since the decision which track to attend is made very early in Germany, at a stage when the age of school entry effect is unlikely to have dissipated, the date of birth may, through its link to age of school entry, affect the track students attend after elementary school and, given the limited possibilities of switching during grades 5 through 9 , lock them into a particular track throughout middle school (see the first effect in Figure 2). Hence, the first stage of our analysis addresses the difference in track assignment through grades 5 and $9, T$, between children born in month $Z$, where $Z_{i}=1$ if the individual is born in July rather than June:

$$
\pi=E\left[T_{i} \mid Z_{i}=1\right]-E\left[T_{i} \mid Z_{i}=0\right]
$$

We then investigate the impact of birth month on long-term labour market outcomes like wages and unemployment. The reduced-form of our analysis is the difference in these longterm outcomes (denoted by $Y$ ) between students born in July and those born in June:

$$
\eta=E\left[Y_{i} \mid Z_{i}=1\right]-E\left[Y_{i} \mid Z_{i}=0\right]
$$

To guide the interpretation of this reduced-form effect, consider the following 'causal' model of track attendance and long-term outcomes:

$$
Y_{i}=a_{0}+a_{1 i} T_{i}+a_{2} S S A_{i}+a_{3} A_{i}+u_{i}
$$


where $S S A_{i}$ denotes school starting age and $A_{i}$ denotes scholastic ability, both of which determine selection into tracks and are thus correlated with $T_{i}$. For simplicity, we restrict the effects of school starting age and ability on long-term outcomes to be constant across individuals, but allow the effect of track attendance to vary across individuals. Suppose that date of birth is as good as randomly assigned and therefore independent of potential outcomes and track attendance so that $E\left[A_{i} \mid Z_{i}=1\right]=E\left[A_{i} \mid Z_{i}=0\right]$. We provide evidence in favor of this independence assumption below. Under this assumption, and distinguishing between three tracks, low $(L)$, medium $(M)$ and high $(H)$, the reduced-form effect of date of birth on long-term outcomes equals ${ }^{8}$

$$
\begin{aligned}
\eta= & \left(\operatorname{Pr}\left(L_{i} \mid Z_{i}=0\right)-\operatorname{Pr}\left(L_{i} \mid Z_{i}=1\right)\right) \underbrace{E\left[Y_{i}^{M}-Y_{i}^{L} \mid M_{i} \text { if } Z_{i}=1, L_{i} \text { if } Z_{i}=0\right]}_{\text {LATE, } M \text { vs } L}+ \\
& \left(\operatorname{Pr}\left(H_{i} \mid Z_{i}=1\right)-\operatorname{Pr}\left(H_{i} \mid Z_{i}=0\right)\right) \underbrace{E\left[Y_{i}^{H}-Y_{i}^{M} \mid H_{i} \text { if } Z_{i}=1, M_{i} \text { if } Z_{i}=0\right]}_{\text {LATE, } H \text { vs } M}+ \\
& \underbrace{a_{2}\left(E\left[S S A_{i} \mid Z_{i}=1\right]-E\left[S S A_{i} \mid Z_{i}=0\right]\right)}_{\text {long-term effect of SSA }}
\end{aligned}
$$

The first term captures the causal impact of attending the medium rather than the low track in middle school on the long-term outcomes for those individuals who attend the medium track if born in July but the low track if born in June (i.e., $E\left[Y_{i}^{M}-Y_{i}^{L} \mid M_{i}\right.$ if $Z_{i}=1, L_{i}$ if $\left.Z_{i}=0\right]$ ), multiplied with the share of children shifted between these two tracks because of month of birth (i.e., $\operatorname{Pr}\left(L_{i} \mid Z_{i}=0\right)-\operatorname{Pr}\left(L_{i} \mid Z_{i}=1\right)$ ). Similarly, the second term represents the local average treatment effect of attending the high rather than the medium track in middle school for those individuals who attend the high track if born in July but the medium track if born in June, multiplied with the share of individuals shifted between these two tracks because of their birth month. If delayed school entry conveys advantages or disadvantages

\footnotetext{
${ }^{8}$ Here, we have assumed that no individuals are shifted from the low to the high track because of their month of birth. We also require monotonicity, implying that no individuals are shifted to a less advanced track because they are older at school entry.
} 
even in adulthood, the reduced-form estimate additionally captures this direct effect of school starting age (the third term in equation (2)).

The EXCLUSION RESTRICTION While we focus our discussion on the reduced form estimates, we can obtain the impact of track assignment in middle school on long-term outcomes by dividing the reduced-form effect by the first-stage effect, $\tau=\eta / \pi$. As equation (2) shows, the interpretation of this parameter as the causal impact of track assignment on long-term outcomes requires an additional assumption to the independence assumption (exclusion restriction), namely that that school starting age affects long-term outcomes solely through track assignment in middle school (i.e., $a_{2}=0$ ). There are two reasons why this assumption may be violated. First, if date of birth, through the interaction between age of school entry and compulsory school leaving laws, affects the length of formal schooling (see the third effect in Figure 2, implying $a_{2}<0$ ). This is the case in the U.S., where students are allowed to leave school at the day of their 16 th birthday. ${ }^{9}$ In Germany, however, this effect is absent, since students must stay in school until they at least complete 9th grade (as opposed to their 16th birthday, as in the U.S.).

Second, the exclusion restriction would also be violated if being older at school entry has a direct impact on long-run outcomes that does not operate through track assignment in middle school (see the second effect in Figure 2, implying $a_{2}>0$ ). We have reviewed more than 30 articles that study the impact of age at school entry on achievements. This literature has found direct effects of age of school entry on long-run (prime age) earnings or educational attainment to be either non-existent or positive. ${ }^{10}$ None of the papers we have reviewed finds a negative effect of being older at school entry on short- or longer term outcomes. ${ }^{11}$ Therefore,

\footnotetext{
${ }^{9}$ This feature of the U.S. education system was first exploited in the seminal paper by Angrist and Krueger (1991), who use date of birth as an instrument for the length of formal schooling.

${ }^{10}$ Studies that find positive effects of age of school on educational attainment or earnings include Bedard and Dhuey (2012), and Frederickson and Öckert (2014). Black, Devereux, and Salvanes (2011), in contrast, find little effect of age of school entry on educational attainment and earnings for individuals older than 30.

${ }^{11}$ This is apart from the mechanical effect that is instigated through individuals who are older at school entry also being older at labor market entry, so that they have, at any given age, accumulated less labor market experience than individuals who are younger at school entry, see e.g. Frederickson and Öckert (2013)
} 
even if the initial advantages of delayed school entry indeed persisted into adulthood, these effects are likely to be positive, leading to an upward bias in our estimates. Because we do not find a significantly positive effect of date of birth on long-term outcomes, this reasoning reinforces our finding that a more advanced track assignment in middle school has no positive effects on adult outcomes.

The IndEPEndEnCE ASSUMPtion The causal interpretation of the reduced-form estimate (and thus the IV estimate) further hinges on the independence assumption, which in our baseline specification entails that whether a child is born in June or July is random. In the regression discontinuity estimates that exploit the exact date of birth (see below), the independence assumption requires that whether a child is born just before or just after the school entry cut-off date (i.e., on June 30 or July 1) is random. Note that since we are comparing individuals born within the same season, this independence assumption is considerably weaker here than in studies that use birth quarter as an instrument.

This assumption could be violated if parents timed the birth of their children to take advantage of a later school start age. This is unlikely in our case, as the school entry rule was not rigidly enforced and parents could decide against that rule if they felt strongly about it. To assess more formally whether the independence assumption is violated, we have implemented a test for bunching of births around the age of school entry cut-off, based on McCrary (2008). We find no evidence for bunching. For instance, when using a bandwidth of 20 days, we obtain a discontinuity between June 30 and July 1 of 0.0052 (in log difference), with a standard error of 0.0038 . We obtain similar estimates for any day between May 1st and August 31st. ${ }^{12}$

and Black, Devereux, and Salvanes (2011). We eliminate this experience effect using various methods (see Section 5.2 for details), so that our estimates of the impact of track assignment in middle school on wages are not affected by this mechanism.

${ }^{12}$ These estimates are based on the number of individuals born on a given day observed in the social security data and therefore include only those individuals who at least once had a job covered by the social security system. Hence, a discontinuity could potentially arise for two reasons: first, because parents may time their births to take advantage of age of school entry rules. Second, because delayed school entry might affect the probability of having held at least one job within the social security system. Our findings suggest 
We have also compared the parental characteristics of children born in July versus those born in June using German Microcensus data for 2005 (see Table A1). We find no significant differences between children born in July and those born in June in terms of parental education and their age at the children's birth.

The Group of Compliers Equation (2) illustrates that the reduced form estimates are informative about the causal long-term effects of attending a more advanced track for a particular group of individuals: those individuals who attend a more or less advanced track because of their birth month. Who are these 'compliers'? Students at the top of the (expected) ability distribution are likely to attend the high track, whereas students at the bottom of the distribution are likely to attend the low track, regardless of their date of birth. Hence, the compliers are likely to be students at the margin between two tracks. This group is particularly interesting because it consists of children whose teachers and parents may be unsure of which track the student should attend after elementary school and who are therefore most at risk of misallocation - and for whom small differences in the perceived learning potential at the end of elementary school could potentially lead to large differences in adult outcomes.

We develop a stylised model of track choice in Appendix B which formalises the shifting of students to a different track because of birth month; this model is not necessary to understand the paper, but formalises the intuition outlined above (see Proposition 1 and Figure A3). The model also clarifies how the key differences between school tracks (i.e., teaching technology, peer quality and teacher quality) and the costs of switching between tracks may affect completed education (see Proposition 2) and long-term labour market outcomes (see Proposition 3).

that neither is important. 


\subsection{Implementation}

\section{Reduced-Form Estimates}

To implement our empirical strategy, we estimate reduced-form effects $\eta$ by replacing the population means in equations (1) and (2) with their sample means, while controlling for birth year and gender effects. ${ }^{13}$ We also report regression discontinuity estimates that exploit the student's exact date of birth. ${ }^{14}$ Specifically, we estimate regressions of the following type:

$$
Y_{i}=\alpha_{0}+h\left(\operatorname{Day}_{i}\right)+\alpha_{1} \text { Post }_{i}+x_{i}^{\prime} \alpha_{2}+u_{i} .
$$

Here, Day ${ }_{i}$ is the student's date of birth (normalised to be 0 on the school entry cut-off date, July 1$), h($.$) is a polynomial function of birthday,$ Post $_{i}$ is an indicator variable equal to 1 if the student was born on or after July 1 , and $x_{i}$ is a control variable vector that includes birth year and gender effects. The parameter of interest is $\alpha_{1}$, the impact of being born after the school entry cut-off date (i.e., on or after July 1) on long-term outcomes. We first estimate equation (3) on a sample of all students and then restrict the sample to students born within three months of the school entry cut-off date (i.e., to students born between April and September). We approximate the function $h\left(\right.$ Day $\left._{i}\right)$ as a polynomial function of various orders. As suggested by Lee and Card (2007), we cluster standard errors at the date of birth level. ${ }^{15}$

First-Stage Estimates

Due to lack of precise information on date of birth in the German Microcensus (see Section 4.2), we are not able to estimate the same specifications for the first-stage estimates for the same birth cohorts. We instead compare track attendance in middle school of students born

\footnotetext{
${ }^{13}$ Our results remain almost unchanged if we exclude these control variables from the regressions.

${ }^{14}$ We cannot do this for the first-stage effect because our data sets provide information only on birth month or whether the pupil was born earlier or later during the year; see Sections 4.2 and 4.3 for details.

${ }^{15}$ Our baseline estimate comparing individuals born in June with those born in July may also be seen as a regression discontinuity estimate in which the sample is restricted to students born within two months of the school entry cut-off date and the birthday effect $(h($.$) in equation (3)) is assumed to be constant.$
} 
earlier (i.e., between January and April) and later (i.e., between May and December) during the year (instead of June/July). In Section 5.1, we provide evidence that this is likely to lead to an underestimate in the first-stage estimates, which causes bias away from zero in the estimate of our local average treatment effect $\hat{\tau}$.

\section{DATA}

Our empirical analysis combines four main data sources, described below. Throughout the analysis, we exclude foreign citizens from our sample because they may have migrated to Germany after beginning school and thus may not have been affected by the school entry cut-off date. Since a different age of school entry cut-off rule applied in East Germany, we further restrict the sample to West German residents.

\subsection{Social Security Records}

Our primary data used to estimate the reduced-form equations (see equation (2)), which relate long-term outcomes to date of birth, come from three decades of social security records, covering 1975 to 2006. These data, collected for every individual covered by the social security system, include detailed information on variables such as education, wages, unemployment, occupation, and the exact date of birth. Not included are civil servants, the self-employed, and military personnel. A comparison of the number of observations in the Social Security Records and the number of births in the Birth Register data suggests that at least $84 \%$ individuals enter the data base at some point in their career. ${ }^{16}$

From this data base, we select all men and women born between 1961 and 1976. The 1961 cohort is the first cohort for which the effective school entry cut-off falls between June and July. The 1976 cohort is 30 years old in the last year of our data and should thus have completed post-secondary education. For these cohorts, we observe the entire

\footnotetext{
${ }^{16}$ This is the average of the ratio between the number of individuals in the social security data-which exclude foreign citizens-and the number of total births in West Germany-which include foreign citizens-and thus provides a lower bound for the share of West German citizens who enter the data base at some point.
} 
work history from labour market entry onwards, which allows precise computation of their potential and actual labour market experiences. The wage variable refers to April 30 of each year and is deflated using the Consumer Price Index, with 1995 as the base year. ${ }^{17}$ We distinguish four educational categories: "no post-secondary education" refers to individuals who graduated from the low or medium track and did not complete an apprenticeship; "apprenticeship" includes individuals who completed an apprenticeship (as part of the formal German vocational education system) but did not complete college or university, regardless of track completed; ${ }^{18}$ and 'college' and 'university' refer to individuals who have graduated from four-year college or five-year university, respectively. Our unemployment variable refers to registered unemployment.

\subsection{Microcensus}

Our second data come from the scientific use files of the German Microcensus for 1976, 1978, 1980, 1982, 1985, and 1987. We use these data to estimate the first-stage equations (see equation (1)) which relates track assignment in middle school to date of birth. We restrict the sample to the same birth cohorts as for the social security records, 1961 to 1976. Rather than specifying the exact birth month, the Microcensus provides only a binary indicator for individuals' being born either during the January through April period or the May through December period. Comparing these two periods is likely to yield an underestimate of the first-stage since the school entry cut-off falls in June/July. We assess this using data from the recent School Census for Bavaria and Hesse, which do contain information on birth month, but are unfortunately not available for the earlier school cohorts studied here.

\footnotetext{
${ }^{17}$ In our data, up to 5 percent of the observations are top-coded at the highest wage level for which social security contributions must be paid. In imputing the censored part of the wage distribution, we assume that residuals are normally distributed and allow for heterogeneity in the variance by age group; see Dustmann, Ludsteck and Schönberg (2009) for details.

${ }^{18}$ An apprenticeship in Germany is a structured 2-3 years training program for a particular occupation that combines on the job training in a firm with certified training personnel and state-provided academic education specific to the chosen occupation.
} 


\subsection{School Census}

The School Census for Bavaria and Hesse covers all students attending general and vocational schools in these two German states. It is available for the academic school years 2004/05 to 2008/09 for Bavaria, and for the academic school years 2002/03 to 2008/09 for Hesse. The data set does include information on track and grade attended, as well as on birth month. We use these data to assess the downward bias in our first-stage estimates resulting from the lack of exact birth month information in the Microcensus data, for the 1990 to 1994 birth cohorts in Bavaria and the 1988 to 1994 birth cohorts in Hesse, respectively. We also use them to illustrate the impact of birth month on the probability that the student graduates from a specialised or general high track school, for the 1986-1987 birth cohorts in Bavaria and the 1984-1987 birth cohorts in Hesse, respectively.

\subsection{Census}

Our fourth data source is the 1987 census which, unlike the social security records, contains information on the school track individuals graduated from. Like the German Microcensus, however, the 1987 census (the last census in Germany before the 2011 census) includes no information on exact birth month, asking respondents instead whether they were born before or after May 24. We use these data to estimate the effect of being born later versus earlier in the year on the probability that the student graduates from a low, medium or high track school for the 1961 to 1963 birth cohorts who were between 24 and 26 years old at the time of the census and should thus have completed their secondary education. Unlike the School Census, the 1987 Census does not allow us to distinguish between graduation from a general or specialised high track school. 


\section{$5 \quad$ Results}

\subsection{The Impact of Date of Birth on Track Assignment in Middle School}

We first investigate the effect of date of birth on track assignment in middle school, which is the first stage of our analysis. Since the opportunities to switch tracks between grade 5 and 9 are limited (see Section 2.2), we proxy track assignment in middle school by the track attended at age 14 .

Our results in Panel A of Table 2, based on the German Microcensus, show that children born later in the year (May through December) are 2.0 percentage points more likely to attend a high track at age 14 and 1.9 percentage points less likely to attend a low track at age 14 than children born earlier in the year (January through April), for a total effect of 3.9 percentage points. As Table A2 shows, this effect is strongly persistent throughout grades 5 to 9. Based on data from the School Census, the estimates indicate that the effect of date of birth on track assignment is roughly constant throughout middle school. ${ }^{19}$

Since the Microcensus lacks information on birth month, these estimates compare children born before and after the end of April, rather than children born before June 30th and after June 30th. As discussed in Section 4.2, this is likely to lead to underestimation in our first-stage regression because it introduces measurement error in the age of school entry. We investigate this possibility using the School Census, which contains information on birth month (although only for recent cohorts who have not entered the labour market yet). Using this data source, we find that children born in July are 5.2 percentage points more likely to attend a high track school and 4.2 percentage points less likely to attend a low track than children born in June, for a total effect of 9.4 percentage points (row (i) of Panel B, Table

\footnotetext{
${ }^{19}$ It follows from these estimates that birth month roughly shifts as many students between the low and the medium track $\left(\operatorname{Pr}\left(L \mid Z_{i}=0\right)-\operatorname{Pr}\left(L \mid Z_{i}=1\right)=0.019\right)$ as between the medium and high track $\left(\operatorname{Pr}\left(H \mid Z_{i}=1\right)-\operatorname{Pr}\left(H \mid Z_{i}=0\right)=0.020\right)$. This implies that the relative weight for the local average treatment effect on long-term outcomes of attending a medium as opposed to a low track school is $0.49(0.019 / 0.039)$, while the relative weight for the local average treatment effect of attending a high as opposed to a medium track school is $0.51(0.020 / 0.039)$.
} 
2). ${ }^{20}$ If instead we reconstruct the same aggregation as in the Microcensus and compare the track assignment of children born between May and December with those born between January and April, we find a smaller first-stage estimate of 7.2 percentage points (row (ii) of Panel B, Table 2). This suggests indeed that the first-stage estimate of 3.9 percentage points in Panel A of Table 2 is likely to be an underestimate of the impact of date of birth on track attendance.

Even after adjusting for measurement error, the first-stage results for the recent cohorts in the School Census appear stronger than those for the older cohorts in the Microcensus (7.2 vs. 3.9 percentage points). In Appendix A. 2, we provide evidence that this difference can be fully explained by the earlier cohorts' being less compliant with the school entry age cut-off rule than the more recent cohorts. Hence, the mechanism generating the date-of-birth effect on track choice - namely, that age of school entry increases the likelihood of attending a more advanced track - seems to be similar for both earlier and more recent cohorts.

\subsection{Date of Birth, Track Assignment in Middle School, and Long-Term labour Market}

\section{Outcomes}

The previous section shows that the date of birth has a precisely estimated and sizable effect on track assignment in middle school, with at least 3.9 percent of students shifted to a different track because of their date of birth. Thus, since the differences between tracks are large (see Section 2.3), and since only the high track leads to direct admission at colleges and universities, we would expect to find sizeable effects of date of birth on long-term labour market outcomes, such as wages, employment and occupational choice. This is what we investigate in this section, starting with the impact on wages. Our analysis draws on data

\footnotetext{
${ }^{20}$ The effect of date of birth is further illustrated in Figure A1 in Appendix A. 1, where we display the share of 14-year-olds attending a high (Panel A) or a low (Panel B) track by month of birth. The figure shows a clear discontinuity in track assignment around the June/July school entry cut-off date, confirming that the differences in track assignment between June- and July-born children are indeed driven by differences in age of school entry.
} 
from the social security records, and restricts the sample to men aged 30 and over. ${ }^{21}$

WAGES One problem with assessing the effect of date of birth and hence track assignment on wages is that individuals who are born in July start school later, and hence enter the labour market later, so that they have, at any given age, accumulated less labour market experience than individuals born in June. Panel A of Figure 3 illustrates this effect, where we plot raw log-wages (i.e., wages unadjusted for the experience) against date of birth, restricting the sample to men who are employed full-time. The figure shows a clear wage disadvantage for men born just after the school entry cut-off date (i.e., in July), since they have accumulated less experience than individuals born just before the school entry cut-off date (i.e., in June). To isolate the causal effect of track choice in middle school on wages, we need to eliminate this experience effect. In Panel B of Figure 3, we plot log wages adjusted for differences in experience, where we get rid of the experience effect by first estimating the returns to potential experience based on a 4th order polynomial using OLS and then subtracting these estimates from raw log wages. Panel B no longer shows a discontinuity around the school entry cut-off date. Thus, date of birth, and hence the track attended throughout middle school, has no noticeable impact on experience-adjusted wages for the marginal student.

Table 3 (Panel A) confirms this conclusion and presents reduced-form estimates for different specifications of Equation (3). While in column (1), we simply compare outcomes of individuals born in July with those of individuals born in June, the estimates in columns (2) to (6) differ by birth month sampling window (January-December in columns (2), (3) and (5); April-September in column (4) and (6)) and the order of the date of birth polynomial included as a control in the discontinuity regression (5th order, 6th order, 2nd order and linear in columns (2), (3), (4)/(5), and (6) respectively). Further, estimates in columns (5)

\footnotetext{
${ }^{21}$ We focus on men because, as explained below, isolating the effect of track attendance in the reduced-form effect given by Equation (2) requires the estimation of returns to potential experience. This is particularly challenging for women, due to the changing selection of women into work over the life cycle.
} 
and (6) allow the slope of the control function $\left(h\left(\right.\right.$ Day $\left.\left._{i}\right)\right)$ to change at the age of school entry cut-off date.

In row (i) of Panel A we present estimates on raw wages unadjusted for experience. As illustrated in Figure 3, individuals born just after the school entry cut-off date earn less than individuals born just before the school entry cut-off date according to all specifications. However, once we adjust wages for experience as shown in row (ii), all reduced-form estimates are statistically insignificant and closely centered around zero, ranging from (negative) $0.1 \%$ in specifications (1) and (4) to (pos.) $0.03 \%$ in specification (5). ${ }^{22}$ These very small reducedform estimates suggest that - despite the stark differences between tracks - the impact of track attendance in middle school on wages is close to zero for the marginal student. Provided that the exclusion restriction holds (see Section 3.1), we can obtain point estimates of the impact of track attendance in middle school by dividing the reduced-form estimates in Table 3 by the (likely underestimated) first-stage estimate of 0.039. These Two Sample-2SLS estimates are likewise close to zero, ranging from from (negative) $2.5 \%$ (specification (1)) to (pos.) $0.9 \%$ (specification (5)), with $95 \%$ confidence intervals of $[-0.074,0.024]$ and $[-0.050$, 0.068], respectively. ${ }^{23}$

Next, we show that the reduced-form estimates remain close to zero no matter how we account for the difference in potential experience of individuals born shortly before and shortly after the age of school entry cut-off. In Figure 4, we plot the difference in unadjusted log wages between individuals born in June and July against age, for men born between 1961 and 1964 whom we follow into the labour market until they are at least 42 years

\footnotetext{
${ }^{22}$ In these regressions, older cohorts receive more weight than younger cohorts (e.g., individuals from the 1961 cohort are observed for a maximum of 16 years, whereas individuals from the 1976 cohort are observed at most once). To give each cohort the same weight in the regressions, we have re-estimated the regressions in Table 3, but collapsing all valid wage spells for an individual into one average wage. These equally weighted estimates are very similar to those reported in Table 3 once we adjust for experience.

${ }^{23}$ We compute the variance of the TS-2SLS estimate $\widehat{\tau}$ as

$\operatorname{Var}[\widehat{\tau}]=\operatorname{Var}\left[\frac{\widehat{\eta}}{\widehat{\pi}}\right]=\frac{\widehat{\pi}^{2} \operatorname{Var}(\widehat{\eta})+\widehat{\eta}^{2} \operatorname{Var}(\widehat{\pi})}{\widehat{\pi}^{4}}$, whose square root is the estimate of the standard error (when variances in the formula must be replaced by their estimates). Note that both the point estimates and the lengths of the confidence intervals are likely to be exaggerated, as the first-stage estimate of 0.039 is underestimated, as we explain above.
} 
of age. The figure clearly shows that for young ages, individuals born in July earn lower wages than individuals born in June, due to lower labour market experience of July born individuals. However, this differential decreases with age and disappears in the late 30s, reflecting the flattening out of wage-age profiles at higher ages. In Table 4, we present additional estimates which use alternative ways of adjusting the raw log wage differential for differences in potential experience, focusing on individuals born within one month of each side of the age of school entry cut-off, as in column (1) of Table 3. In column (2) of Table 4, we allow for a more flexible functional form using a set of dummy variables to model the returns to potential experience (instead of a 4th order polynomial as in column (1)). Results are almost identical. In columns (3) and (4), we restrict the sample to individuals aged 40 years and older whose wages are flat with respect to potential experience. In line with Figure 4, for these individuals, both the raw and experience-adjusted wage differentials are very small and not statistically significant from zero. Our reduced-form estimates of the impact of date of birth on wages therefore do not depend on the particular way we eliminate the experience effect.

Other labour market outcomes In Panel B of Table 3 we investigate the impact date of birth may have, through track attendance in middle school, on other labour market outcomes, focusing on the share of days in registered unemployment and the share of days spent working since labour market entry (where we down-weight part-time work relative to full-time work), and current occupational choice (where we distinguish between blue- and white-collar occupations). Like results in Panel A, results refer to men aged 30 and over, ${ }^{24}$ but now include, for the unemployment and experience outcomes, all men who ever entered the data base, ${ }^{25}$ and for occupational choice, all men observed in the data at a given age (as working full-time, part-time or as registered unemployed). While the effects of birth month

\footnotetext{
${ }^{24}$ We find very similar results when women are included in the sample.

${ }^{25}$ That is, if an individual does not work for a whole year at age, say, 35, we assign zero working days throughout this spell when computing the share of days spent working.
} 
(through track attendance in middle school) on labour force participation and unemployment are interesting in their own right, large effects on these outcomes could also potentially bias the wage results which refer only to men who at a given age are working full-time. The estimates show that the effect of date of birth on the share of days spent in unemployment or working is basically zero in all specifications. Thus, track assignment appears to have little effect on labour force participation or unemployment. For instance, when dividing the reduced-form estimates by the first-stage estimate of 0.039, the Two Sample-2SLS estimates of track attendance in middle school on the share of days spent working since labour market entry range from 0.016 (s.e.: 0.016; column (1)) and -0.005 (s.e.: 0.019; columns (2) and (3)). Furthermore, these results imply that our wage results in Panel A do not suffer from a selection bias into employment.

We report results for occupational choice in row (iii). Historically, the low track prepared students for apprenticeships in blue-collar occupations, whereas the medium track prepared them for apprenticeships in white-collar occupations (see Section 2.2). Yet, the reduced-form effect of date of birth on the probability that an individual works in a white collar profession is close to zero.

Overall, therefore, our findings show that date of birth has little impact on a variety of long-term labour market outcomes, such as wages, occupational choice, and unemploymentalthough it has a strong impact on the type of track attended in middle school. This points at students who have been mis-tracked due to their birth month to adjust their initial track allocation at a later stage in their educational career. Our discussion in Section 2.2 highlights that the German school system has a number of built-in possibilities that allow for such retracking after grade 9 or 10 . We now investigate whether and to what extent such up- and downgrading takes place. 


\subsection{Up- and Downgrading}

As discussed above, the German education system allows for two upgrading possibilities from medium to high track schools after middle school (i.e., after 10th grade), by changing to general high track schools, i.e. the same schools attended by high track students throughout middle school, and by attending specialised high track schools, i.e. schools specifically designed for graduates from medium track schools to gain access to college or university (see Figure 1). There may also be downgrading, through leaving a high track school after 10th grade or by not enrolling in college or university after graduating from a high track school.

Movements between the Medium and High Track: We first investigate movements between the medium track and general high track at the end of middle school, drawing on data from the School Census. In Panel A of Table 5, row (i) we contrast the difference between students born in July and June in the probability of attending the high track in middle school (proxied by track attendance at age 14) with the difference in the probability of graduating from the general high track (measured at age 22). The figures point to a substantial amount of movements between the medium and general high track: whereas children born in July are 5.2 percentage points more likely to attend the high track in middle school (see also our first-stage estimates in Panel B and row (i) of Table 2), they are only 2.0 percentage points more likely to graduate from that track. This decline could either be due to downgrading of July-born students who attend the high track in middle school and leave that track after 10th grade, or due to an upgrading of June-born students who attend the medium track in middle school and enroll in a general high track school after 10th grade. Since the share of students who are enrolled in the high track in middle school is roughly the same as the share of students who graduate from a general high track school (around 36\% according to own calculations based on the School Census for Bavaria and Hesse), the decline reflects both an 
upgrading of students born in June, and a downgrading of students born in July. ${ }^{26}$

These numbers consider movements between the medium and general high track only. Next, we additionally investigate movements between the medium and specialised high track. Remarkably, the difference between June- and July-born children disappears entirely once we include students who graduate from a specialised high track school in our measure for high track completion (row (ii) in Panel A). This suggests that, for marginal students who attend a different track because of their date of birth, the track attended in middle school has no impact on the probability of graduating from any high track school that grants access to college or university. It also points to the important role that specialised high track schools play in explaining why track attendance in middle school has little impact on long-term outcomes. Also note that our calculations based on the School Census for Bavaria and Hesse show that the share of students who graduate from a general or specialised high track is at around $52 \%$, considerably larger than the share of students who attend the high track in middle school (around 36\%). This suggests that both July- and June-born students upgrade from the medium to the specialised high track, but June-born students do so more frequently than July-born students.

The finding so far refers to recent birth cohorts who have not entered the labour market yet. We also confirm similar movements between the medium and any high track at the end of middle school for earlier cohorts, using data from the 1987 Census (row (iii) in Panel A): whereas being born later during the year (the 1987 Census does not contain exact information on birth month) increases the probability of attending a high track school during middle school by 2.0 percentage points (see our first-stage estimate in Panel A of Table 2), it has no impact on the probability of completing a general or specialised high track school.

Movements between the Low and Medium Track: As discussed in Section 2.2, the German school system also provides an opportunity to upgrade from a low to a medium

\footnotetext{
${ }^{26}$ Since the School Census does not contain student identifiers, we are not able to investigate transitions between the medium and general high track directly.
} 
track school after 9th grade. We investigate movements between these two tracks in Panel B of Table 5, drawing again on data from the 1987 Census. The results indicate that there is also a substantial amount of movement between the low and medium track: whereas children born in July are 1.9 percentage points more likely to attend at least the medium track in middle school than children born in June (see our first-stage estimate in Panel A of Table 2 ), they are only 0.3 percentage points more likely to graduate from at least a medium track school.

Downgrading after Graduation from the High Track: A third adjustment possibility exists after graduation from a (specialised or general) high track school in the form of choosing not to pursue a college or university education. We investigate this form of downgrading in Figure 5, where, based on data from the social security records, we plot the share of students who do not attend college - although they graduated from a high track school (general or specialised) — against date of birth. The figure reveals a clear discontinuity around the school entry cut-off date: among individuals who graduated from a high track school, those born after the cut-off date are about 0.7 percentage points more likely not to complete college or university than individuals born after the cut-off date.

In sum, these results provide strong evidence that students who are shifted to a more or less advanced track in middle school because of their date of birth make use of the flexibilities built into the German tracking system: they revise their track choices made after elementary school at later stages in the educational career, both in the form of upgrading to a more advanced track at the end of middle school and in the form of downgrading by not enrolling in college or university after graduation from a high track school.

\subsection{Date of Birth, Track Assignment in Middle School and Highest Degree Completed}

Given the substantial amount of up- and downgrading of marginal students after middle school, how does the track attended in middle school affect the highest degree completed? We investigate this in Figure 6 where we plot the highest degree completed against date of 
birth, using data from the social security records. The sample consists of all men and women who ever entered the social security data base. ${ }^{27}$ We distinguish between three disjoint post-secondary education outcomes: no post-secondary education (Panel A), apprenticeship (Panel B, the typical pathway for graduates from the low or medium track), college or university (Panel C, the typical pathway for graduates from the specialised or general high track). Remarkably, neither figure shows a clear discontinuity around the school entry cutoff date (the vertical line), suggesting that the up- and downgrading that takes place after middle school fully eliminates the impact of date of birth, and hence the track attended in middle school, on education completed. ${ }^{28}$

We report the corresponding reduced-form estimates in Table 6, using the same specifications as in Table 3. All specifications yield similar results, and confirm the overall picture apparent from Figure 5 that date of birth has no evident impact on education completed. ${ }^{29}$ Interestingly, being born in July rather than June (and thus being older at school entry) appears to have, if at all, a negative effect on university or college education. This is fully consistent with the downgrading we illustrate in the previous section.

\section{Discussion and Conclusions}

Although a tracking system may be more efficient in tailoring education to the needs of students than a comprehensive system, it has the inherent problem of misallocating students to tracks because of incomplete or erroneous information about the student's learning potential at the time of the tracking decision. This problem may be addressed by the school system if it allows for possibilities to revise initial choices at a later stage, through providing students whose potential is higher (or lower) than initially projected with opportunities to switch

\footnotetext{
${ }^{27}$ Results are very similar if we exclude women from the sample.

${ }^{28}$ The figures reveal strong seasonal effects, with children born in April or May generally outperforming children born in January, similar to those documented by Buckles and Hungerman (2013). Note that, as emphasized in Section 3, seasonal effects do not pose a threat to our identification strategy as long as it is random whether a woman gives birth just before or just after the school entry cut-off date July 1 .

${ }^{29}$ The effects of track choice can be easily obtained by dividing these coefficients by the first stage estimate of 0.039 .
} 
tracks.

Our paper is the first to analyze the long-term effects of such flexibilities for a tracking system that seems not only to be among the most rigorous, but that also tracks students earliest, around the age of 10 . At the same time, this tracking system has an array of built-in possibilities that allow students to modify initial choices at a later stage, after middle school.

Our results suggest that, for these marginal students (i.e. students that are close to the threshold between two different tracks), the track attended in middle school has no impact on long-term outcomes such as wages, days worked, unemployment, or occupational choice. We provide evidence that this is because these students take advantage of the flexibilities built into the tracking system, and demonstrate that re-tracking takes the form of both an upgrading of marginal students from the middle to the high track after 10th grade, and a downgrading of students who complete the high track but fail to enroll in college or university. Due to this up- and downgrading, the track attended in middle school has little effect on highest degree completed for marginal students.

Not only are our results important for the debate on the merits and disadvantages of tracking systems, they also suggest that marginal students can make up for substantial weaknesses in earlier education provided they gain access to high quality schools and universities at later stages in their educational careers-even if the exposure to a less challenging school environment is prolonged (in our case 5-6 years) and the differences between school environments in terms of teaching technology and peer and teacher quality are large.

\section{University College London}

University College London, IAB Nuremberg and IZA, Bonn

Leibniz Universität Hannover, CReAM, University College London, SEW University of St. Gallen and IZA, Bonn 


\section{REFERENCES}

[1] Abdulkadiroglu, A., J. D. Angrist, and P. A. Pathak (2011). 'The Elite Illusion: Achievement Effects of Boston and New York Exam Schools', NBER Working Paper 17264.

[2] Altonji, J., T. Elder and C. Taber (2005). 'Selection on Observed and Unobserved Variables: Assessing the Effectiveness of Catholic Schools', Journal of Political Economy, vol. 113(1), pp. 151-184.

[3] Angrist, J. D. and A. B. Krueger (1991). 'Does Compulsory School Attendance Affect Education and Earnings?', Quarterly Journal of Economics, vol. 106(4), pp. 9791014.

[4] Bedard, K. and E. Dhuey (2006). 'The Persistence of Early Childhood Maturity: International Evidence of Long-term Age Effects', Quarterly Journal of Economics, vol. 121(4), pp. 1437-1472.

[5] Bedard, K. and E. Dhuey (2012). 'School Entry Policies and Skill Accumulation across Directly and Indirectly Affected Individuals', Journal of Human Resources, vol. 47(3), pp. 583-612.

[6] Betts, J. (2011). 'The Economics of Tracking in Education', Chapter 7 of Handbook of the Economics of Education, Vol. 3, E. A. Hanushek, S. Machin, and L. Wössmann (ed.), North-Holland.

[7] Black, S., P. Devereux, and K. G. Salvanes (2013). 'Under Pressure: The Effect of Peers on Outcomes of Young Adults', Journal of Labor Economics, vol. 31(1), pp. 119-153.

[8] Black, S., Devereux, P. and K. G. Salvanes (2011). 'Too Young to Leave the Nest: The Effects of School Starting Age', Review of Economics and Statistics, vol. 93(2), pp. 455-467.

[9] Buckles, K. and D.M. Hungerman (2013). 'Season of Birth and Later Outcomes: Old Questions, New Answers', Review of Economics and Statistics, vol. 95(3), pp. 711724.

[10] Bundesagentur für Arbeit (2004). 'Arbeitsmarkt 2003', Amtliche Nachrichten der Bundesagentur für Arbeit.

[11] Chetty, R., Friedman, J.N., Hilger, N.. Saez, E., Whitmore Schanzenbach, D. and D. Yagan (2011). 'How Does Your Kindergarten Classroom Affect Your Earnings? Evidence from Project Star', Quarterly Journal of Economics, vol. 126(4), pp. 15931660 .

[12] Chetty, R., Friedman, J.N., and J. Rockoff. 2011. 'The Long-Term Impacts of Teachers: Teacher Value-Added and Student Outcomes in Adulthood', NBER Working Paper 17699 .

[13] Clark, D. (2010). 'Selective Schools and Academic Achievement', B.E. Journal of Economic Analysis $\&$ Policy, 10 (Advances), Article 9. 
[14] Crawford, C., L. Dearden, and C. Meghir (2007). 'When You Are Born Matters: The Impact of Date of Birth on Child Cognitive Outcomes in England', London: Institute for Fiscal Studies.

[15] Cullen, J., B. Jakob, and S. Levitt (2005). 'The Impact of School Choice on Student Outcomes: An Analysis of the Chicago Public Schools', Journal of Public Economics, vol. 89(5-6), pp. 729-760.

[16] Cullen, J., B. Jakob, and S. Levitt (2006). 'The Effect of School Choice on Student Outcomes: Evidence from Randomized Lotteries', Econometrica, vol. 74(5), pp. 1191-1230.

[17] Deming, D. (2011). 'Better Schools, Less Crime?', Quarterly Journal of Economics, vol. 126(4), pp. 2063-2115.

[18] Deming, D., Hastings, J., Kane, T. and D. Staiger (2012). 'School Choice, School Quality, and Academic Achievement', Harvard Graduate School of Education, mimeo.

[19] Duflo, E., P. Dupas and M. Kremer (2011). 'Peer Effects, Teacher Incentives, and the Impact of Tracking: Evidence from a Randomized Evaluation in Kenya', American Economic Review, vol. 101(5), pp. 1739-1774.

[20] Dustmann, C., J. Ludsteck and U. Schönberg (2009). 'Revisiting the German Wage Structure', Quarterly Journal of Economics, vol. 124(2), pp. 843-881.

[21] Elder, T. E. and D. H. Lubotsky (2009). 'Kindergarten Entrance Age and Children's Achievement: Impacts of State Policies, Family Background, and Peers', Journal of Human Resources, vol. 44(3), pp. 641-683.

[22] Evans, W. and R. Schwab (1995). 'Finishing High School and Starting College: Do Catholic Schools Make a Difference?', Quarterly Journal of Economics, vol. 110(4), pp. 941-974.

[23] Figlio, D. N. and M. E. Page (2002). 'School Choice and the Distributional Effects of Ability Tracking: Does Separation Increase Inequality?', Journal of Urban Economics, vol. 51(3), pp. 497-514.

[24] Fredriksson, P. and B. Öckert (2014). 'Life-Cycle Effects of Age of School Start', Economic Journal, vol. 124(579), pp. 977-1004.

[25] Gould, E. D., V. Lavy, and M. D. Paserman (2004). 'Immigrating to Opportunity: Estimating the Effect of School Quality Using a Natural Experiment on Ethiopians in Israel', Quarterly Journal of Economics, vol. 119(2), pp. 489-526.

[26] Guyon, N, Maurin, E. and S. McNally (2012). 'The Effect of Tracking Students by Ability into Different Schools: A Natural Experiment', Journal of Human Ressources, vol. 47(3), pp. 684-721.

[27] Hall, C. (2012). 'The Effects of Reducing Tracking in Upper Secondary SchoolEvidence from a Large-Scale Pilot Scheme', Journal of Human Resources, vol. 47(1), pp. 237-269. 
[28] Hanushek, E. A. and L. Wössmann (2006). 'Does Educational Tracking Affect Performance and Inequality? Differences-in-Differences Evidence Across Countries', Economic Journal, vol. 116(510), pp. C63-C76.

[29] Imbens, G. and J. Angrist (1994). 'Identification and Estimation of Local Average Treatment Effects', Econometrica, vol. 62(2), pp. 467-475.

[30] Inoue, A. and G. Solon (2010). 'Two-Sample Instrumental Variables Estimators', Review of Economics and Statistics, vol. 92(3), pp. 557-561.

[31] Jackson, C. K. (2010). 'Do Students Benefit from Attending Better Schools? Evidence from Rule-Based Student Assignments in Trinidad and Tobago', Economic Journal, vol. 120(549), pp. 1399-1429.

[32] Kerr, S.P., Pekkarinen, T., and R. Uusitalo (2013). 'School Tracking and Development of Cognitive Skills', Journal of Labor Economics, vol. 31(3), pp. 577-602.

[33] Lavy, V. and A. Schlosser (2011). 'Mechanisms and Impacts of Gender Peer Effects at School', American Economic Journal: Applied Economics, vol. 3(2), pp. 1-33.

[34] Lee, D.S. and D. Card (2007). 'Regression Discontinuity Inference with Specification Error', Journal of Econometrics, vol. 142(2), pp. 655-674.

[35] Malamud, O. and C. Pop-Eleches (2011). 'School Tracking and Access to Higher Education among Disadvantaged Groups', Journal of Public Economics, vol. 95(11-12), pp. 1538-1549.

[36] McCrary, J. (2008). 'Manipulation of the Running Variable in the Regression Discontinuity Design: A Density Rest', Journal of Econometrics, vol. 142(2), pp. 698-714.

[37] Mühlenweg, A.M. and P.A. Puhani (2010). 'The Evolution of the School-Entry Age Effect in a School Tracking System', Journal of Human Resources, vol. 45(2), pp. 407-435.

[38] Neal, D. (1997). 'The Effects of Catholic Secondary Schooling on Educational Achievement', Journal of Labor Economics, vol. 15(1), pp. 98-123.

[39] Pop-Eleches, C. and M. Urquiola (2013). 'Going to a Better School: Effects and Behavioral Responses', American Economic Review, vol. 103(4), pp.1289-1324.

[40] Puhani, P. A. and A. M. Weber (2007). 'Does the Early Bird Catch the Worm? Instrumental Variable Estimates of Early Educational Effects of Age of School Entry in Germany', Empirical Economics, vol. 32(2), pp. 359-386.

[41] Schanzenbach-Whitmore, D. (2009). 'Experimental Estimates of Peer Effects', Mimeo, Northwestern University.

[42] Schneeweiss, N. and M. Zweimüller (2014). 'Early Tracking and the Misfortune of Being Young', Scandinavian Journal of Economics, vol. 116(2), pp. 394-428.

[43] Waldinger, F. (2007). 'Does Ability Tracking Exacerbate the Role of Family Background for Students' Test Scores?', Mimeo, University of Warwick. 


\section{A Appendix: Additional Results}

-Table A1 here-

-Table A2 here-

\section{A. 1 The Impact of Birth Month and Track Assignment in Middle School}

Figure A1 plots the share of students who at age 14 were attending the high (Panel A) or the low (Panel B) track against birth month based on the school census data. The figure shows a clear discontinuity in track choice around the school entry cut-off date: children born in July are 5.2 percentage points more likely to attend the high track and 4.2 percentage points less likely to attend the low track than children born in June, for a total effect of 9.4 percentage points.

-Figure A1 here-

\section{A. 2 Comparison of First Stage for Recent Cohorts (School Census) and Older Cohorts} (Microcensus)

A comparison of the estimates in Panel A and Panel B of Table 2 clearly indicates a stronger impact of date of birth on track choice for the recent birth cohorts in Bavaria and Hesse than for the older birth cohorts in West Germany, even taking into account the measurement error in the school entry cut-off $(9.4 \% \text { versus } 5.0 \%)^{30}$. We next investigate whether this difference can be explained by the older cohorts being less being less compliant with the school entry cut-off rule than the more recent birth cohorts. Because Bavaria does not record the year of school entry, meaning we cannot compute its compliance rate, we restrict the analysis to Hesse, whose first-stage estimate is 7.3 percent (compared to a 9.4 percent first-stage estimate for Hesse and Bavaria combined). The compliance rate for the recent birth cohorts in Hesse is 33.5 percent, whereas that for the older birth cohorts (here proxied by the 1963 birth cohort in the 1970 Census for West Germany) is only 21.9 percent. ${ }^{31}$ To estimate the impact of relative age (i.e., being one year older at school entry) on track choice, we divide the effect of birth month on track choice by the effect of birth month on age of school entry and obtain an effect of 23.0 percentage points $(0.050 / 0.219)$ for the older birth cohorts. For the younger birth cohorts, we estimate a very similar number: 21.8 percentage points $(0.078 / 0.335)$. Hence, the lower first-stage results for the 1961-1976 cohorts in West Germany than for the recent cohorts in Bavaria and Hesse are wholly explained by the older cohorts being less compliant with the school entry age cut-off rule than more recent cohorts.

\footnotetext{
${ }^{30}$ The latter number is computed as follows. By dividing the first-stage estimate based on children born in June or July of $9.4 \%$ (Table 2, Panel B, row (i), column (3)) with the first-stage estimate based on children born earlier or later during the year of $7.2 \%$ (Table 2, Panel B, row (ii), column (3)), we can derive an adjustment factor of $1.29(0.094 / 0.072)$. Multiplying the estimates in Panel A by this adjustment factor indicates that, for the 1961 to 1976 birth cohorts, children born in July are 5 percentage points more likely to attend a more academic middle school than students born in June.

${ }^{31}$ Children in the 1963 cohort who were born July through December should not yet have been in school when the census was carried out in spring 1970, whereas children born January through June should have already been attending school. However, regressing an indicator for school attendance on an indicator for being born in July or June results in a coefficient of only 0.219 ; that is, a compliance with the school entry cut-off rule of 21.9 percent.
} 


\section{A. 3 Birth Month and Graduation from the Higher School Track}

Because the school census contains no direct information on degrees obtained, we proxy graduation from the general high track by first counting the number of students who, by age 17, 18, and onward, had ever attended a general high track school in grade 13, making sure not to double count students who repeated a grade. Because students drop out of the census on leaving school, we divide this number by the total number of children born in the month, year, and state. We proxy graduation from a specialised high track school as the ratio of the number of students who, by age 22 , had ever attended a specialised high track school in grade 12 to the total number of children born in the month, year, and state:

$$
\widehat{p}=\frac{\# \text { ever reached grade } 13(12)}{\# \text { births }}
$$

The standard error of this share is estimated as the square root of

$$
\operatorname{Var}(\widehat{p})=\frac{\widehat{p}(1-\widehat{p})}{\# \text { births }}
$$

The variance of the difference in the shares between July and June born children is given by

$$
\operatorname{Var}\left(\widehat{p}_{\text {July }}-\widehat{p}_{\text {July }}\right)=\frac{\widehat{p}_{\text {July }}\left(1-\widehat{p}_{\text {July }}\right)}{\# \text { births July }}+\frac{\widehat{p}_{\text {June }}\left(1-\widehat{p}_{\text {June }}\right)}{\# \text { births June }}
$$




\section{B Model Appendix}

\section{B. 1 Set-up}

Our model assumes three periods: periods 1 and 2, which are schooling periods, and period 3 , which is the working period. The beginning of the first period corresponds to the end of elementary school (grade 4) when parents decide on which type of middle school their child should attend. The end of this period corresponds to the end of middle school (grade 9 or 10) when children have the opportunity to switch tracks. The second period corresponds to the period of secondary education, and all children enter the labor market at the beginning of period 3. This setup, it should be noted, assumes that the tracks are of equal length, an assumption motivated by our focus on the impact of the learning environment, and of track switching, on long-term outcomes. For simplicity, we distinguish only two tracks, low $(L)$ and high $(H)$.

In this model, children differ in both their 'ability', denoted by $a$, and month of birth, which here is limited to children born in June or July. In line with the independence and exclusion assumptions discussed in Section 3.1, at the beginning of period 1, when the initial track choice is made, children born in July outperform children born in June by $\Delta$, but by the beginning of period 2, when the initial decision can be revised, this advantage has disappeared.

LeArning about Children's Ability: The children's ability is initially uncertain. At the beginning of period 1, parents receive a noisy signal (e.g., a school grade) about their child's ability, denoted by $\theta$, expressed as $\theta_{i}=a_{i}+\varepsilon_{i}$ for children born in July and $\theta_{i}=a_{i}-\Delta+\varepsilon_{i}$ for children born in June. Parents use this signal to update their own beliefs about their child's ability; updated beliefs are denoted here by $\hat{a}=E[a \mid \theta]$. Assuming that $a_{i}$ and $\varepsilon_{i}$ are normally distributed with mean $\mu$ and variance $\sigma_{a}^{2}$ and with mean zero and variance $\sigma_{\varepsilon}^{2}, E[a \mid \theta$, July $]=\hat{a}=\frac{\sigma_{a}^{2} \theta+\sigma_{\varepsilon}^{2} \mu}{\sigma_{a}^{2}+\sigma_{\varepsilon}^{2}}$ for children born in July, and $E[a \mid \theta$, June $]=\hat{a}=\frac{\sigma_{a}^{2}(\theta+\Delta)+\sigma_{\varepsilon}^{2} \mu}{\sigma_{a}^{2}+\sigma_{\varepsilon}^{2}}$ for children born in June. This formula reflects that if the same signal is observed for two students, one is born in June and the other in July, the student born in June has a higher expected ability. We use $G(\hat{a})$ and $F(a \mid \hat{a})$, respectively, to denote the cumulative distribution functions of the updated ability $\hat{a}$ and the true ability $a$, conditional on $\hat{a}$. $G(\hat{a})$ is normally distributed with mean $\mu$ and variance $\frac{\sigma_{a}^{4}}{\sigma_{a}^{2}+\sigma_{\varepsilon}^{2}}$, while $F(a \mid \hat{a})$ is normally distributed with mean $\hat{a}$ and variance $\frac{\sigma_{a}^{2} \sigma_{\varepsilon}^{2}}{\sigma_{a}^{2}+\sigma_{\varepsilon}^{2}}$. By the end of the first period, the child's ability is fully revealed, and parents and children can revise their track choice accordingly.

Switching Costs: Switching from a low to a high track school, however, can be costly. Conversely, we assume that moving down from a high to a low track school is costless. We distinguish between two types of switching costs, institutional switching costs $\left(c^{i}\right)$ and academic switching costs $\left(c^{a}\right)$. Institutional switching costs reflect the restrictions the education system puts on upgrading from the low to the high track. For instance, a very rigid tracking system may not offer students the possibility to move up from the low to the high track, amounting to infinite institutional switching costs. Even if the tracking system provides students with opportunities to upgrade, it may be academically costly to do so, reflecting that the less intensive and less abstract teaching method at a low track school (see Section 2.2) 
may make it difficult for students to keep up with the more advanced learning material at a high track school. We model institutional switching costs as a utility cost which students incur once at the end of period 1 when switching from the low to the high track. In contrast, academic switching costs are modeled as a productivity cost which students incur both in period 2 while in school and in period 3 while working.

Differences between Tracks-Peers: We summarise the productivity or performance of June- versus July-born students in each school track and each period in Table A3. We focus on the two most important differences between the two tracks: teaching technology and peers (see Table 1). ${ }^{32}$ To model peer effects, we use a standard linear-in-means peer model in which a higher average peer ability increases the productivity of all students in the same way. We assume that parents take the expectations of the average ability of students in each school type as a given, thereby ignoring the possibility that they can manipulate other parents' expectations through their own track choice. Let $\hat{\Pi}_{t}^{j}$ denote parental expectations about the average ability of peers in track $j(j=L, H)$ in period $t(t=1,2)$. To contrast parental expectations from the average ability which is realised in equilibrium, we denote the latter by $\Pi_{t}^{j}$. We allow the contemporaneous effect on productivity of peers in period 1 or 2 to differ from their effect on productivity in future periods, and denote the effects of peers to whom students are exposed in period $t$ on productivity in period $k$ by $\gamma_{t}^{k}$.

Differences Between Tracks-Teaching Technology: To model the differences in teaching technology between the school tracks, we assume that learning technology is more sensitive to ability in a high than in a low track school. Specifically, the learning technology in the two tracks is linear in the student's ability $a$ and thus is given by $\alpha^{j}+\beta^{j} a$, with $j=L, H$ and $\alpha^{L}>\alpha^{H}$ and $\beta^{L}<\beta^{H}$. These assumptions reflect the fact that the teaching technology in a low track school is more adapted to children who are drawn from the lower part of the ability distribution.

As an example, contrast the productivity in period 3 of an individual who attended a low track school in period 1 and a high track school in period $2\left(\alpha^{H}+\beta^{H} a+\gamma_{2}^{3} \hat{\Pi}_{2}^{H}+\gamma_{1}^{3} \hat{\Pi}_{1}^{L}-c^{a}\right)$ with that of an individual of the same ability who attended a high track school in both periods $\left(\alpha^{H}+\beta^{H} a+\gamma_{2}^{3} \hat{\Pi}_{2}^{H}+\gamma_{1}^{3} \hat{\Pi}_{1}^{H}\right)$. The difference in the productivity between these two individuals reflects the direct effect of the track attended in period 1, conditional on the track attended in period 2, on the long-term outcomes in period 3. According to our set-up, this effect operates through two channels: first, the individual who attended a high track school in both periods has been exposed to better peers in period 1, which may boost labor market performance even when both individuals received the same type of education in period 2 (compare $\gamma_{1}^{3} \hat{\Pi}_{1}^{L}$ and $\gamma_{1}^{3} \hat{\Pi}_{1}^{H}$ ). Second, the individual who attended a high track school in both periods has not suffered the academic cost $\left(c^{a}\right)$ of upgrading from a low to a high track school.

\footnotetext{
${ }^{32}$ Teacher effects can be easily incorporated in our model. Better teachers have a similar effect as better peers.
} 


\section{B. 2 Equilibrium}

At the beginning of periods 1 and 2, parents (or in period 2, students) choose the track that will yield the highest lifetime utility, which we model as the sum of the student's utility in each period. For simplicity, we assume that in each period, student utility is equal to student productivity (as described in Table A3) minus the institutional switching costs and ignore discounting. ${ }^{33}$

Period 2 Decision: First, we analyze the parents' decision problem at the beginning of period 2, when the student's ability is fully known. Because in period 2, there is no difference between children born in June and those born in July, the decision problem is the same for both groups. Consider first a student who attended a high track school in period 1 who thus does not have to bear the switching costs if she wants to continue at a high track school in period 2. Figure A.2 illustrates the decision problem. In the figure, we plot, using the solid lines, the student's utility from attending a high or a low track school in period 2 against her ability $a$. Since the teaching technology in a high track school is more sensitive to ability than in a low track school (i.e., $\beta^{H}>\beta^{L}$ ), the student's utility in a high track school is increasing in ability at a faster rate than in a low track school. Hence, there is an ability threshold $a_{H}^{*}$ such that all students whose ability is identified as below $a_{H}^{*}$ sort into low track schools, while all students whose ability is identified above $a_{H}^{*}$ upgrade to a high track school.

Formally, a student who attended a high track school in period 1 prefers a low over a high track school in period 2 if her utility at a low track school exceeds that at a high track school:

$$
\underbrace{\alpha^{L}+\beta^{L} a+\gamma_{1}^{2} \hat{\Pi}_{1}^{H}+\gamma_{2}^{2} \hat{\Pi}_{2}^{L}} \quad+\quad \underbrace{\alpha^{L}+\beta^{L} a+\gamma_{1}^{3} \hat{\Pi}_{1}^{H}+\gamma_{2}^{3} \hat{\Pi}_{2}^{L}}
$$

flow utility in period 2 , low track in period 2 flow utility in period 3 , low track in period 2

$$
\underbrace{\alpha^{H}+\beta^{H} a+\gamma_{1}^{2} \hat{\Pi}_{1}^{H}+\gamma_{2}^{2} \hat{\Pi}_{2}^{H}} \quad+\quad \underbrace{\alpha^{H}+\beta^{H} a+\gamma_{1}^{3} \hat{\Pi}_{1}^{H}+\gamma_{2}^{3} \hat{\Pi}_{2}^{H}}
$$

flow utility in period 2 , high track in period 2 flow utility in period 3 , high track in period 2

Solving for $a_{H}^{*}$ yields

$$
a_{H}^{*}=\frac{2\left(\alpha^{L}-\alpha^{H}\right)-\left(\gamma_{2}^{2}+\gamma_{2}^{3}\right)\left(\hat{\Pi}_{2}^{H}-\hat{\Pi}_{2}^{L}\right)}{2\left(\beta^{H}-\beta^{L}\right)}
$$

Note that the quality of peers the student was exposed to in period $1\left(\hat{\Pi}_{1}^{H}\right)$ affect the student's utility in a high and low track school in period 2 equally, and thus do not affect the student's switching decision.

Next, we consider a student who attended a low track school in period 1 . This student has to bear the institutional and academic switching costs when upgrading from a low to a high track school in period 2. This lowers her utility in a high track school, as indicated by the dashed line in Figure A2. It follows that the ability threshold at which this student is indifferent between the two tracks, $a_{L}^{*}$, is above the threshold at which the student who

\footnotetext{
${ }^{33}$ More generally, student utility could in each period be a positive monotonic transformation of student productivity, meaning that the transformation could differ in each period.
} 
attended a high track in period 1 is indifferent between the two tracks, $a_{H}^{*}$. It is easy to show that the difference between the two indifference thresholds is increasing in the switching costs:

$$
a_{L}^{*}=a_{H}^{*}+\frac{c^{i}+c^{a}}{2\left(\beta^{H}-\beta^{L}\right)}
$$

Period 1 Decision: Next, we consider the parents' decision problem in period 1, when the student's ability is uncertain. Here, parents take into account the optimal switching behavior in period 2 and choose a low over a high track school if the child's expected utility of attending a low track school exceeds that of attending an high track school. In Section B. 5, we again show that a threshold exists such that all students with expected ability below the threshold attend a low track school, whereas all students with expected ability above the threshold attend a high track school. Because of the initial disadvantage faced by June-born students in period 1, this threshold is smaller for students born in July than for those born in June, $\widehat{a}_{\text {July }}^{*}<\widehat{a}_{\text {June }}^{*}$.

We illustrate the impact of month of birth on track choice in period 1 in Figure A3. Students with expected ability below $\widehat{a}_{\text {July }}^{*}$ attend a low track school in period 1 no matter whether they are born in June or July ('never takers'). In contrast, students whose expected ability falls above $\widehat{a}_{\text {June }}^{*}$ attend a high track school in period 1 regardless of their date of birth ('always takers'). Students who are shifted from a low to a high track school because of a July birth ('compliers') are students with expected ability between $\widehat{a}_{\text {July }}^{*}$ and $\widehat{a}_{\text {June }}^{*}$ who are close to indifferent between the two tracks. This leads to the following proposition:

Proposition 1: Students who are shifted between tracks because of their month of birth ('compliers') are students whose expected ability falls close to indifferent between school tracks, in the range $\left[\widehat{a}_{\text {July }}^{*}, \widehat{a}_{\text {June }}^{*}\right]$.

See Section B. 5 for an illustration.

Note that in this model, parents send their June-born child with expected ability between $\widehat{a}_{\text {July }}^{*}$ and $\widehat{a}_{\text {June }}^{*}$ to a low track school even though they know that their child would have attended a high track school had she been born in July, and even though they know that the initial disadvantage of a younger age at school entry fully disappears by the end of the first period. Why are parents willing to do this? In our model, the answer is that when deciding which type of school their child should attend, parents take into account the student's utility in the first period. ${ }^{34}$ Hence, parents trade off a higher utility in the present for a lower utility in the future. Alternatively, we could assume that parents are unaware that students born in June perform more badly on average at the beginning of period 1 than students born in July simply because they are younger. In this case, parents may base their school type decision for period 1 solely on the signal $\theta$ and ignore that a child born in June who has the

\footnotetext{
${ }^{34}$ This was one of the key arguments of Larry Summers in the "Tiger Mom" debate. Quoting from Gerard Baker's article "Larry Summers vs. the Tiger Mom" in the Wall Street Journal of January 29, 2011, "People on average live a quarter of their lives as children. That's a lot," Mr. Summers said. "It's important that they be as happy as possible during those 18 years. That counts too."'
} 
same school grades as a child born in July (but is relatively younger) has a higher expected ability. Modeling track choice in period 1 in this way has no impact on the key results for our model.

\section{B. 3 Implications}

We now turn to the implications of the model, beginning with the impact of track attendance in period 1 on track attendance in period 2 .

TRACK COMPletion: Consider the local average treatment effect of attending a high track school in period 1 (denoted by $H_{1}$ ) on the probability of completing that track (i.e., of attending an $H$ school in period 2, denoted by $H_{2}$ ). Dividing the reduced-form effect (i.e. $\operatorname{Pr}\left(H_{2} \mid Z_{i}=\right.$ July) $-\operatorname{Pr}\left(H_{2} \mid Z_{i}=\right.$ June $)$ ) by the first-stage effect (i.e. $\operatorname{Pr}\left(H_{1} \mid Z_{i}=\mathrm{July}\right)$ $\operatorname{Pr}\left(H_{1} \mid Z_{i}=\right.$ June) $)$, which corresponds to equations (1) and (2) in Section 3.2, yields

$$
\frac{\operatorname{Pr}\left(H_{2} \mid Z_{i}=1\right)-\operatorname{Pr}\left(H_{2} \mid Z_{i}=0\right)}{\operatorname{Pr}\left(H_{1} \mid Z_{i}=1\right)-\operatorname{Pr}\left(H_{1} \mid Z_{i}=0\right)}=\frac{\int_{\hat{a}_{\text {July }}^{*}}^{\hat{a}_{\text {une }}^{*}}\left(F\left(a_{L}^{*} \mid \hat{a}\right)-F\left(a_{H}^{*} \mid \hat{a}\right)\right) d G(\hat{a})}{G\left(\hat{a}_{\text {June }}^{*}\right)-G\left(\hat{a}_{\text {July }}^{*}\right)}
$$

This effect depends on the difference between the thresholds $a_{L}^{*}$ and $a_{H}^{*}$, which in turn depends on the switching costs $c^{i}$ and $c^{a}$ (see equation (B-1)). The higher the switching costs, the larger the difference between the thresholds $a_{L}^{*}$ and $a_{H}^{*}$, and the larger the impact of track attendance in period 1 on track attendance in period 2 . If there are no switching costs, then $a_{L}^{*}=a_{H}^{*}$ and the track attended in period 1 has no impact on track completion. We summarise our findings the following proposition: ${ }^{35}$

Proposition 2: The local average treatment effect of attending a high track in period 1 on attending that track in period 2 increases in the academic and institutional switching costs.

WAGE EfFEcts: Consider the local average treatment effect of attending a high (versus a low) track school in period 1 on wages (assumed to be equal to productivity) in period 3 , which we again obtain by dividing the reduced-form effect (i.e. $\operatorname{Pr}\left(w_{3} \mid Z_{i}=1\right)-\operatorname{Pr}\left(w_{3} \mid Z_{i}=\right.$

\footnotetext{
${ }^{35}$ This intuitive argument considers only the direct effect of switching costs on track completion through its effect on $a_{L}^{*}$ and $a_{H}^{*}$ and ignores that switching costs also affect the ability thresholds $\hat{a}_{\text {July }}^{*}$ and $\hat{a}_{\text {June }}^{*}$. We have confirmed the positive relationship between switching costs and the impact of the track attended in period 1 on the track attended in period 2 by running extensive simulations that take these indirect effects into account.
} 
1)) by the first-stage effect:

$$
\begin{aligned}
& \frac{E\left(w_{3} \mid Z_{i}=1\right)-E\left(w_{3} \mid Z_{i}=0\right)}{\operatorname{Pr}\left(H_{1} \mid Z_{i}=1\right)-\operatorname{Pr}\left(H_{1} \mid Z_{i}=0\right)}=\underbrace{\gamma_{1}^{3}\left(\hat{\Pi}_{1}^{H}-\hat{\Pi}_{1}^{L}\right)}_{\text {peers }} \\
& +\underbrace{\frac{\int_{\hat{a}_{\text {July }}^{*}}^{\hat{a}_{\text {une }}^{*}}\left(1-F\left(a_{L}^{*} \mid \hat{a}\right)\right) c^{a} d G(\hat{a})}{G\left(\hat{a}_{\text {June }}^{*}\right)-G\left(\hat{a}_{\text {July }}^{*}\right)}}_{\text {academic switching costs }}+ \\
& \left.\int_{\hat{a}_{\text {July }}^{*}}^{\hat{a}_{\text {une }}^{*}}\left(F\left(a_{L}^{*} \mid \hat{a}\right)-F\left(a_{H}^{*} \mid \hat{a}\right)\right)\left(\alpha^{H}-\alpha^{L}+\gamma_{2}^{3}\left(\hat{\Pi}_{2}^{H}-\hat{\Pi}_{2}^{L}\right)\right)+\left(\beta^{H}-\beta^{L}\right) \int_{\hat{a}_{H}^{*}}^{\hat{a}_{L}^{*}} a d F(a \mid \hat{a})\right) d G(\hat{a}) \\
& G\left(\hat{a}_{\text {June }}^{*}\right)-G\left(\hat{a}_{\text {July }}^{*}\right) \\
& \text { educational pathway effect }
\end{aligned}
$$

The first term in equation (B-2) reflects the exposure to better peers in period 1 on productivity in period 3 (i.e., $\left.\gamma_{1}^{3}\left(\hat{\Pi}_{1}^{H}-\hat{\Pi}_{1}^{L}\right)\right)$. The second effect reflects the academic of switching from a low to a high track school, weighted by the probability that a 'complier' upgrades to the high track (i.e., $\int_{\hat{a}_{\text {July }}^{*}}^{\hat{a}_{\text {une }}^{*}}\left(1-F\left(a_{L}^{*} \mid \hat{a}\right)\right) c^{a} d G(\hat{a}) /\left(G\left(\hat{a}_{\text {June }}^{*}\right)-G\left(\hat{a}_{\text {July }}^{*}\right)\right)$. These two effects may be viewed as the direct effects of track attendance in period 1 on productivity in period 3 , holding track attendance in period 2 constant. These two effects become larger, the larger the impact of peers in period 1 on productivity in period 3 (i.e., the larger $\gamma_{1}^{3}$ ), and the larger the academic switching $\operatorname{costs} c^{a} .^{36}$

The track attended in period 1 affects wages also through the track attended in period 2. This educational pathway effect, captured by the third term in equation (B-2), becomes larger, the larger the impact of the track attended in period 1 on the track attended in period 2 (i.e., the larger the academic and institutional switching costs, $a_{L}^{*}$ versus $a_{H}^{*}$ ), and the larger the effect of peers in period 2 on wages in period 3 (i.e., $\gamma_{2}^{3}$ ). ${ }^{37}$

Note that if both academic and institutional switching costs are zero, then $a_{L}^{*}=a_{H}^{*}$ and the track attended in period 1 has no impact the track completed in period 2; hence, the third term in (B-2) disappears, as does the second term. The effect of track attendance in period 1 on wages in period 3 reduces to the impact of peers in period 1 on future wages; that is, equation (B-2) becomes $\gamma_{1}^{3}\left(\hat{\Pi}_{1}^{H}-\hat{\Pi}_{1}^{L}\right)$. These observations lead to the following proposition:

Proposition 3: (i) (Direct Effect) The direct effect of attending a high (versus a low) track school in period 1 on wages in period 3, holding constant the track attended in period 2, is larger the higher the importance of peers in period $1\left(\gamma_{1}^{3}\right)$ and the higher the academic switching costs $\left(c^{a}\right)$. (ii) The educational pathway effect of attending a high (versus a low) track school in period 1, operating through track completion in period 2 , on wages in period

\footnotetext{
${ }^{36}$ The intuitive argument here again ignores the effect of the switching costs on the indifference thresholds $\hat{a}_{\text {July }}^{*}$ and $\hat{a}_{\text {June. }}^{*}$. We have confirmed that this relation holds in equilibrium using extensive simulations.

${ }^{37}$ Again, this argument here considers the direct effects only and ignores the effects of $\delta_{2}^{3}$ and $\gamma_{2}^{3}$ on the indifference thresholds, but we confirmed that this relation holds in equilibrium using extensive simulations.
} 
3 is larger the higher the institutional and academic switching costs $\left(c^{a}\right.$ and $\left.c^{i}\right)$ and, provided that switching costs are positive, the higher the importance of peers in period $2\left(\gamma_{2}^{3}\right)$. (iii) If both the academic and institutional switching costs are zero, the overall effect of attending a high track school in period 1 on wages in period 3 is equal to the impact of peers in period 1 on wages in period 3 (i.e., $\left.\gamma_{1}^{3}\left(\hat{\Pi}_{1}^{H}-\hat{\Pi}_{1}^{L}\right)\right)$.

\section{B. 4 Interpretation}

What do our empirical findings imply when viewed through the lens of the model? Recall that we find that the track attended in middle school has little impact on completed education, both because students born in June upgrade and because students born in July downgrade. From Proposition 2, this implies that in the German tracking system, both the institutional and academic switching costs are very small. Our findings in Table 6 further suggest that 'specialised' high track schools, which are designed to provide access to college or university to students from low or medium track schools, are an important reason for this.

Since the track attended in middle school has no impact on track completion, the effect of track attendance in middle school on wages reduces to the effect of peers in middle school (i.e., in period 1) on wages (see Proposition 3 (iii)). Our finding of a small wage effect thus suggests that this effect is close to zero (i.e., $\gamma_{1}^{3}$ in our model are close to zero).

It should be noted that our findings are not informative about the importance of peers students are exposed to after middle school (i.e., about $\gamma_{2}^{3}$ in our model). In principle, our findings are consistent with large peer effects in high school (i.e., period 2 in our model). Our findings imply, however, that conditional on the peers students are exposed to in high school (i.e., in period 2), their peers and teachers in middle school (i.e., in period 1) do not matter. 


\section{B. 5 Illustration of Proposition 1}

Ability Cut-Offs: In period 1, when student ability is uncertain, parents whose child is born in July and has the expected ability $\widehat{a}$ send their child to a high track school if

$$
\begin{aligned}
& \int_{H}^{a_{H}^{*}} a d F(a \mid \hat{a}) \\
& \underbrace{\alpha^{H}+\beta^{H} \hat{a}+\gamma_{1}^{1} \hat{\Pi}_{1}^{H}}_{\text {first period, high track }}+\underbrace{F\left(a_{H}^{*} \mid \hat{a}\right)\left(\alpha^{L}+\beta^{L-\infty}\right.}_{\text {2nd period, downgrade to low track }} \frac{\left.-a_{H}^{*} \mid \hat{a}\right)}{\left.\alpha_{1}^{2} \hat{\Pi}_{1}^{H}+\gamma_{2}^{2} \hat{\Pi}_{2}^{L}\right)}+
\end{aligned}
$$

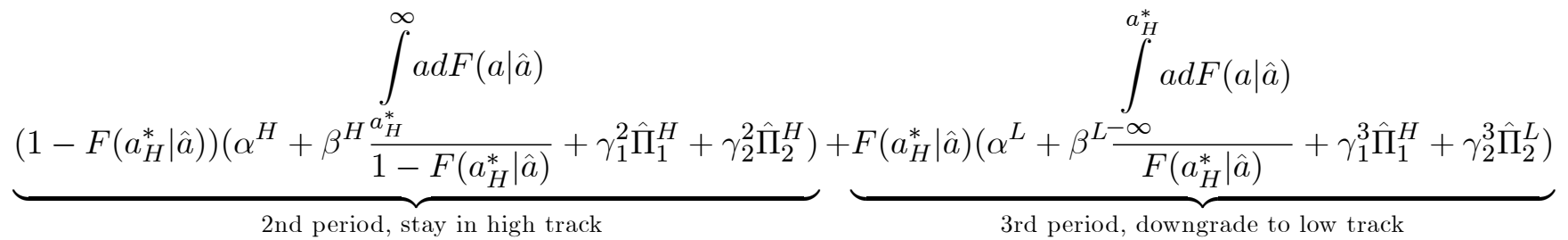

$$
\begin{aligned}
& +\underbrace{\left(1-F\left(a_{H}^{*} \mid \hat{a}\right)\right)\left(\alpha^{H}+\beta^{H} \frac{\int_{a_{H}^{*}}^{\infty} a d F(a \mid \hat{a})}{1-F\left(a_{H}^{*} \mid \hat{a}\right)}+\gamma_{1}^{3} \hat{\Pi}_{1}^{H}+\gamma_{2}^{3} \hat{\Pi}_{2}^{H}\right)}_{\text {3rd period, stay in high track }}> \\
& \underbrace{\alpha^{L}+\beta^{L} \hat{a}+\gamma_{1}^{1} \hat{\Pi}_{1}^{L}}_{\text {first period, low track }}+\underbrace{\int_{L}^{a_{L}^{*}} a d F(a \mid \hat{a})}_{\text {2nd period, stay in low track }} \underbrace{*}_{1} \mid \hat{a})\left(\alpha^{L}+\beta^{L-\infty} \frac{\left.\hat{\Pi}_{1}^{L}+\gamma_{2}^{2} \hat{\Pi}_{2}^{L}\right)}{F\left(a_{L}^{*} \mid \hat{a}\right)}+\right. \\
& \underbrace{\left(1-F\left(a_{L}^{*} \mid \hat{a}\right)\right)\left(\alpha^{H}+\beta^{H} \frac{\int_{L}^{a_{L}^{*}}}{1-F\left(a_{L}^{*} \mid \hat{a}\right)}+\gamma_{1}^{2} \hat{\Pi}_{1}^{L}+\gamma_{2}^{2} \hat{\Pi}_{2}^{H}-c^{i}-c^{a}\right)}+ \\
& \text { 2nd period, upgrade to high track }
\end{aligned}
$$

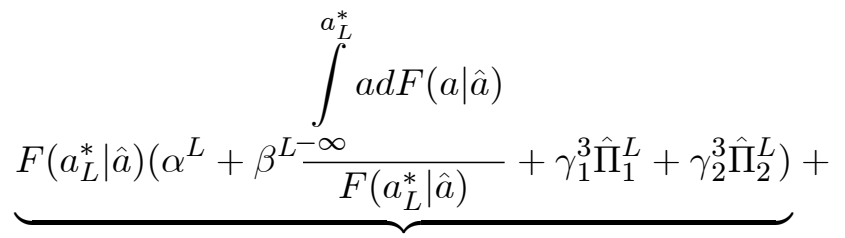

$$
\begin{aligned}
& \text { 3rd period, stay in low track } \\
& \underbrace{\left(1-F\left(a_{L}^{*} \mid \hat{a}\right)\right)\left(\alpha^{H}+\beta^{H} \frac{\int_{a_{L}^{*}}^{\infty} a d F(a \mid \hat{a})}{1-F\left(a_{L}^{*} \mid \hat{a}\right)}+\gamma_{1}^{3} \hat{\Pi}_{1}^{L}+\gamma_{2}^{3} \hat{\Pi}_{2}^{H}-c^{a}\right)}_{\text {3rd period, uporade to high track }}
\end{aligned}
$$


Since the child's utility in a track school is increasing in her expected ability at a faster rate than her utility in a low track school, there exists an ability threshold $\hat{a}_{\text {July }}^{*}$ such that, in period 1, all children whose expected ability is below this threshold attend a low track school while all children whose expected ability is above the threshold attend a high track school.

For a child who is born in June, the parents' decision problem is similar except that the child's utility in the first period in a high and low track school is replaced by $\alpha^{H}+\beta^{H}(\hat{a}-$ $\Delta)+\gamma_{1}^{1} \hat{\Pi}_{1}^{H}$ and $\alpha^{L}+\beta^{L}(\hat{a}-\Delta)+\gamma_{1}^{1} \hat{\Pi}_{1}^{L}$, respectively. It then follows that the expected ability threshold at which children born in June are indifferent between attending a low and high track school in the first period, $\hat{a}_{\text {June }}^{*}$, exceeds the threshold at which children born in July are indifferent; that is, $\hat{a}_{\text {June }}^{*}>\hat{a}_{\text {July }}^{*}$. Consequently, children who are shifted from a low to a high track school because of a July (rather than a June) birth date are children in the expected ability range $\left[\hat{a}_{\mathrm{July}}^{*}, \hat{a}_{\mathrm{June}}^{*}\right]$, as given in Proposition 1.

Expected Versus Realised Peer Quality: In equilibrium, parental expectations of peer ability in each school type and period must correspond to the realised average ability of children in each school type and period; that is, $\hat{\Pi}_{t}^{j}=\Pi_{t}^{j}$. These realised expectations are determined by the ability thresholds $\hat{a}_{\mathrm{July}}^{*} \hat{a}_{\mathrm{June}}^{*}, a_{L}^{*}$, and $a_{H}^{*}$. Next, we illustrate the computation of $\Pi_{t}^{j}$ for students who attend a low track low track school in period $2\left(\Pi_{2}^{L}\right)$. These students fall into four groups: students born in June or July who attended a low track school in period 1 (who have a measure of $\int_{-\infty}^{\hat{a}_{\mathrm{June}}^{*}} F\left(a_{L}^{*} \mid \widehat{a}\right) d G(\widehat{a})$ and $\int_{-\infty}^{\hat{a}_{\mathrm{July}}^{*}} F\left(a_{L}^{*} \mid \widehat{a}\right) d G(\widehat{a})$, respectively), and students born in July or June who attended a high track school in period 1 (who have a measure of $\int_{\hat{a}_{\mathrm{June}}^{*}}^{\infty} F\left(a_{H}^{*} \mid \widehat{a}\right) d G(\widehat{a})$ and $\int_{\hat{a}_{\mathrm{July}}^{*}}^{\infty} F\left(a_{H}^{*} \mid \widehat{a}\right) d G(\widehat{a})$, respectively). The average ability of the first group of students (i.e., students born in June who attend a low track school in period 1 and stay in a low track school in period 2) equals $\int_{-\infty}^{\hat{a}_{\text {June }}^{*}} \int_{-\infty}^{a_{L}^{*}} \frac{a d F(a \mid \widehat{a})}{F\left(a_{L}^{*} \mid \widehat{a}\right)} d G(\widehat{a}) / G\left(\widehat{a}_{\text {June }}^{*}\right)$. 
Hence, $\Pi_{2}^{L}$ equals:

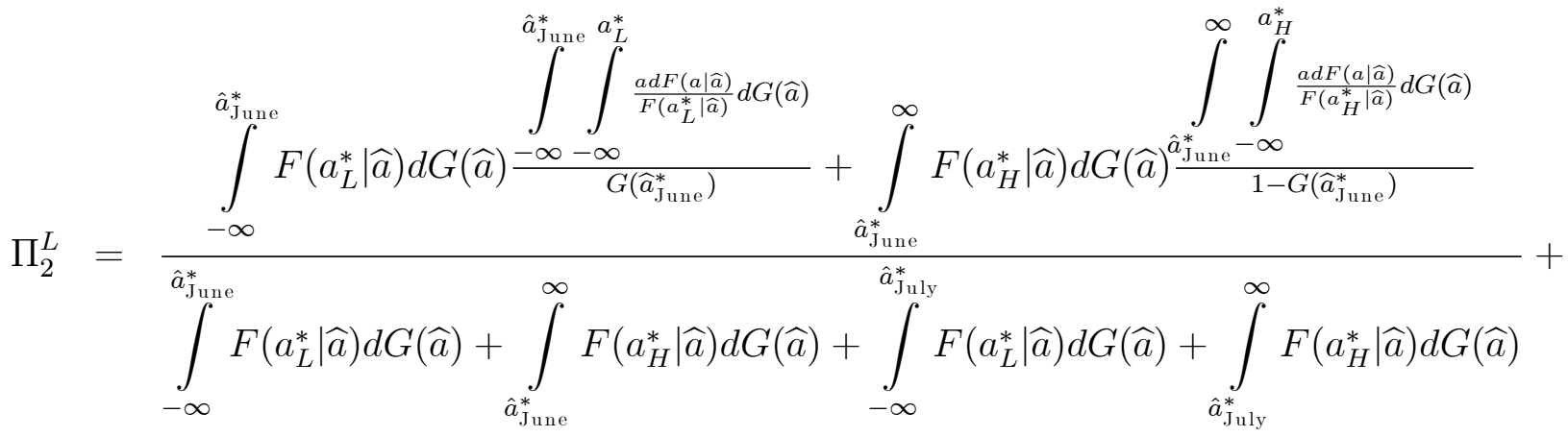

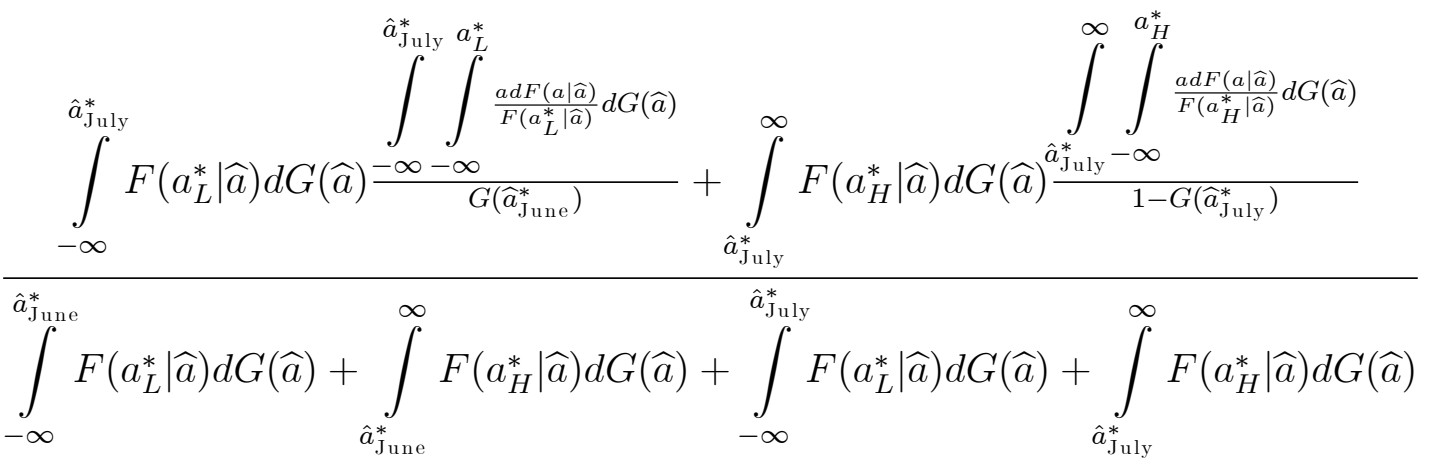

The average ability of the three other groups of students can be computed accordingly. 